HEROES AND MARTYRS OF QUALITY AND SAFETY

\title{
Surgical experience, hospital size and severity adjusted mortality: James Y Simpson, 1869
}

D Neuhauser

Qual Saf Health Care 2005;14:67-68. doi: 10.1136/qshc.2004.013102

$\mathrm{D}$ experienced surgeons have better outcomes? Is mortality lower in "the wards of our (large) palatial hospitals"? To make such comparisons of outcomes of care between providers, it is necessary to adjust for the severity of the patient's illness. Should hospitals with poor results be publicly named? These are some of the hot topics in quality research today. ${ }^{1-3}$

If you visit the handsome Playfair Library Hall of Old College, University of Edinburgh, you will see among the marble busts of 19th century professors and notables that of Sir James Young Simpson MD (1811-1870). Son of a baker in Bathgate Scotland, educated at Edinburgh, qualified as a surgeon at age 18, and elected to the Professorship of Midwifery there in 1840. In 1847 he was appointed "Physician Accoucheur to the Queen for Scotland". He is remembered in Edinburgh today for his introduction of chloroform as an anaesthetic. Queen Victoria received it in April 1853 during childbirth. ${ }^{4}$ His collected published works fill several volumes. Of all this, our interest is in his forgotten comparative study of severity adjusted surgical mortality in 1869.

Simpson sent out survey questionnaires to practising country surgeons in England and Scotland. 374 replies were received. He asked how many amputations they performed, the type of amputation, and whether the patient lived or died. 2098 amputations were reported to him. He collected similar data from small and medium sized hospitals ( 3077 cases) and from 11 large hospitals (2089 cases) in England and Scotland. ${ }^{5}$

\section{Severity of illness}

Amputations were reported in four categories from thigh (the most severe condition), leg, arm and forearm (the least severe condition). Simpson showed a dramatic difference in mortality for these country doctors by case severity (table 1), with a 37 fold difference between the mortality following amputation of the forearm and the thigh. Note in table 1 that the sample sizes for the four types of amputation were all large. Outcome studies often have distributions that approximate the normal, which results in most observations being in the middle and a few at the highest and lowest tails. These high and low extremes are compared. Mortality differences are therefore based on a few observations out of many. Due to the sample sizes and large differences, Simpson's risk adjustment is persuasive.

\section{Experience of the surgeon}

Controlling for case mix (type of amputation), Simpson compared mortality for these country surgeons by experience. The inexperienced surgeons were defined as having performed less than six amputations and more experienced surgeons had performed six or more amputations. Table 2 shows that experienced surgeons had a lower severity adjusted mortality rate for each level of severity.

Table 1 Percentage mortality by type of amputation: 374 country surgeons reporting 2098 cases in Scotland and England, 1869

\begin{tabular}{lll}
\hline Type of amputation & Mortality (\%) & No of cases \\
\hline Thigh & 18.3 & 669 \\
Leg & 13.2 & 618 \\
Arm & 4.3 & 433 \\
Forearm & 0.5 & 378 \\
\hline
\end{tabular}

\section{Hospital size}

Simpson collected amputation mortality data from some of the UK's greatest large teaching hospitals (2089 cases) and from smaller hospitals (3077 cases) and compared amputation mortality by hospital size (table 3 ). The bigger the hospital, the worse the mortality. Table 3 does not adjust for case mix severity, but Simpson does this in his published report to show that case mix differences do not account for these mortality differences by hospital size. The best outcomes were from private country practice "with patients operated on in single or isolated rooms".

\section{Naming and blaming}

The hospitals and their mortality rates are all named by Simpson. To pick one: table 4 shows the mortality for the great Royal Infirmary of Edinburgh associated with Simpson's medical school. The morbidly curious scholar can read about the equally dismal outcomes at the famous St Bartholomew's, Guys', London, and St George's hospitals. Compare the severity adjusted outcomes between tables 1 and 4 to see the good results in non-hospital care compared with big hospitals.

Simpson uses 40 pages answering criticisms of his study. ${ }^{6}$ Some of the issues raised were biased sampling of rural practitioners, recall bias, inadequate severity adjustment, and a lack of understanding of causation.

Table 2 Type of amputation, percentage mortality for inexperienced and experienced surgeons: 374 country surgeons reporting 2098 cases, 1869

\begin{tabular}{|c|c|c|c|c|}
\hline \multirow{2}{*}{$\begin{array}{l}\text { Type of } \\
\text { amputation }\end{array}$} & \multicolumn{2}{|c|}{$\begin{array}{l}\text { Inexperienced surgeons } \\
\text { ( }<6 \text { amputations) } \\
(\mathbf{n}=\mathbf{2 5 5 )}\end{array}$} & \multicolumn{2}{|c|}{$\begin{array}{l}\text { Experienced surgeons } \\
\text { ( } \geqslant 6 \text { amputations) } \\
(n=119)\end{array}$} \\
\hline & No of cases & Mortality (\%) & No of cases & Mortality (\%) \\
\hline Thigh & 193 & 22.7 & 476 & 16.5 \\
\hline Leg & 178 & 18.0 & 440 & 11.3 \\
\hline Arm & 134 & 6.0 & 299 & 3.6 \\
\hline Forearm & 124 & 0.8 & 154 & 0.4 \\
\hline
\end{tabular}


Table 3 Hospital size and amputation mortality

\begin{tabular}{lcc}
\hline $\begin{array}{l}\text { Hospital size } \\
\text { (no of beds) }\end{array}$ & No of amputations & Mortality (\%) \\
\hline $300+$ & 2089 & 41 \\
$201-300$ & 803 & 28 \\
$101-200$ & 1370 & 22 \\
$26-100$ & 761 & 18 \\
$\leqslant 25$ & 143 & 14 \\
Country practice & 2098 & 11 \\
outside hospital & & \\
\hline
\end{tabular}

\section{Achievable results unachieved}

This concept has been championed recently by John Williamson. ${ }^{7}$ Here is how Simpson presents this concept.

"Out of 2089 amputations in big urban hospitals 855 died; out of 2098 amputations in country practice 226 died; giving an excess to hospital practice of 629 deaths"

"This excess ... of 629 deaths in hospital practice as compared to rural practice-in our palatial hospitals as compared with our rural villages and cottages; in large wards as compared to isolated roomsis certainly much greater and more pronounced than I myself expected ... But must the calling of this dismal death-roll still go unchallenged and unchecked? Shall this pitiless and deliberate sacrifice of human life to conditions which are more or less preventable be continued or arrested? Do not these terrible figures plead eloquently and clamantly for a revision and reform of our existing hospital system?"

\section{Process and outcome}

It is not sufficient to observe outcome differences. To correct them we must know the process that leads to their outcomes-the cause and effect. Simpson, like Nightingale, ${ }^{8}$ attributed hospital mortality to overcrowding of patients and associated unsanitary conditions. This was referred to as "hospitalism" and thought to be due to bad air or "miasmas". The acceptance of the germ theory of infection was to come later. With 140 years of hindsight, Simpson's study seems plausible with our current understanding of hospital infection and its control. Semmelweis found out how to reduce this mortality in obstetrics without the understanding of germ theory. ${ }^{9}$ A policy result of Simpson's study
Table 4 Mortality rate by type of amputation, Royal Infirmary Edinburgh, 1859-68

\begin{tabular}{lll}
\hline Type of amputation & No of cases & Mortality (\%) \\
\hline Thigh & 199 & 47.2 \\
Leg & 86 & 44.2 \\
Arm & 28 & 53.6 \\
Forearm & 58 & 20.7 \\
\hline
\end{tabular}

was the British "cottage hospital movement" of the late 1800s which promoted the creation of small rural hospitals.

Today's surgical outcome studies show that high volume larger hospitals often have better outcomes. Simpson found the opposite. This tells us that a simple theory of hospital size and good outcomes is inadequate, and we must look for better theories to explain this relationship across centuries.

Simpson died a hero. An estimated 30000 people attended his funeral in Edinburgh in 1870.

Correspondence to: Professor D Neuhauser, Department of Epidemiology and Biostatistics, Case School of Medicine, Case Western Reserve University, Cleveland, OH 44106-4945, USA; dvn@case.edu

\section{REFERENCES}

1 Luft HS, Garnick DW, Mark DH, et al. Hospital volume, physician volume and patient outcomes. Ann Arbor: Health Administration Press, 1990.

2 Flood AB, Scott WR. Hospital structure and performance. Baltimore: Johns Hopkins University Press, 1987.

3 lezzoni L. Risk adjustment for measuring healthcare outcomes. 3rd ed. Chicago: Health Administration Press, 2003.

4 Liang GH. Sir James Young Simpson and chloroform. New York: Longman's Green \& Co, 1897

5 Simpson JY. Anaesthesia, hospitalism and hermophroditism. The Works of Sir James Y Simpson Bart. Volume II. Edinburgh: Adam and Charles Black, 1871:289-405

6 Simpson JY. Anaesthesia, hospitalism and hermophroditism. The Works of Sir James Y Simpson Bart. Volume II. Edinburgh: Adam and Charles Black, 1871:340-81.

7 Neuhauser D. John Williamson and the terrifying results of the medical practice demonstration project. Qual Saf Health Care 2002;11:387-9.

8 Neuhauser D. Florence Nightingale gets no respect: as a statistician that is. Qual Saf Health Care 2003; 12:317.

9 Best M, Neuhauser D. Ignaz Semmelweis and the birth of infection control, Vienna 1847. Qual Saf Health Care 2004;13:233-4. 